\title{
APPROXIMATING FIXED POINTS OF NON-SELF ASYMPTOTICALLY NONEXPANSIVE MAPPINGS IN BANACH SPACES
}

\author{
YONGFU SU AND XIAOLONG QIN
}

Received 23 March 2006; Revised 9 June 2006; Accepted 10 July 2006

Suppose $K$ is a nonempty closed convex nonexpansive retract of a real uniformly convex Banach space $E$ with $P$ as a nonexpansive retraction. Let $T: K \rightarrow E$ be an asymptotically nonexpansive mapping with $\left\{k_{n}\right\} \subset[1, \infty)$ such that $\sum_{n=1}^{\infty}\left(k_{n}-1\right)<\infty$ and $F(T)$ is nonempty, where $F(T)$ denotes the fixed points set of $T$. Let $\left\{\alpha_{n}\right\},\left\{\alpha_{n}^{\prime}\right\}$, and $\left\{\alpha_{n}^{\prime \prime}\right\}$ be real sequences in $(0,1)$ and $\epsilon \leq \alpha_{n}, \alpha_{n}^{\prime}, \alpha_{n}^{\prime \prime} \leq 1-\epsilon$ for all $n \in \mathbb{N}$ and some $\epsilon>0$. Starting from arbitrary $x_{1} \in K$, define the sequence $\left\{x_{n}\right\}$ by $x_{1} \in K, z_{n}=P\left(\alpha_{n}^{\prime \prime} T(P T)^{n-1} x_{n}+(1-\right.$ $\left.\left.\alpha_{n}^{\prime \prime}\right) x_{n}\right), y_{n}=P\left(\alpha_{n}^{\prime} T(P T)^{n-1} z_{n}+\left(1-\alpha_{n}^{\prime}\right) x_{n}\right), x_{n+1}=P\left(\alpha_{n} T(P T)^{n-1} y_{n}+\left(1-\alpha_{n}\right) x_{n}\right)$. (i) If the dual $E^{*}$ of $E$ has the Kadec-Klee property, then $\left\{x_{n}\right\}$ converges weakly to a fixed point $p \in F(T)$; (ii) if $T$ satisfies condition (A), then $\left\{x_{n}\right\}$ converges strongly to a fixed point $p \in F(T)$.

Copyright (c) 2006 Y. Su and X. Qin. This is an open access article distributed under the Creative Commons Attribution License, which permits unrestricted use, distribution, and reproduction in any medium, provided the original work is properly cited.

\section{Introduction and preliminaries}

Let $E$ be a real Banach space, let $K$ be a nonempty subset of $X$ and $F(T)$ denote the set of fixed points of $T$. A mapping $T: K \rightarrow K$ is said to be asymptotically nonexpansive if there exists a sequence $\left\{k_{n}\right\}$ of positive real numbers with $k_{n} \rightarrow 1$ as $n \rightarrow \infty$ such that

$$
\left\|T^{n} x-T^{n} y\right\| \leq k_{n}\|x-y\| \quad \forall x, y \in K .
$$

This class of asymptotically nonexpansive mappings was introduced by Goebel and Kirk [4]. They proved that if $K$ is a nonempty bounded closed convex subset of a uniformly convex Banach space $E$, then every asymptotically nonexpansive self-mapping $T$ of $K$ has a fixed point. Moreover, the fixed points set $F(T)$ of $T$ is closed and convex.

Many authors have contributed their efforts to investigate the problem of finding a fixed point of asymptotically nonexpansive mapping. In $[8,9]$, Schu introduced a modified Mann iteration process to approximate fixed points of asymptotically nonexpansive 
self-maps defined on nonempty closed convex and bounded subsets of a Hilbert space $H$. More precisely, he proved the following theorems.

Theorem 1.1 (see [8]). Let $H$ be a Hilbert space, $K$ a nonempty closed convex and bounded subset of $H$, and let $T: K \rightarrow K$ be a completely continuous asymptotically nonexpansive with sequence $\left\{k_{n}\right\} \subset[1, \infty), k_{n} \rightarrow 1$, and $\sum_{n=1}^{\infty}\left(k_{n}^{2}-1\right)<\infty$. Let $\left\{\alpha_{n}\right\}_{n=1}^{\infty}$ be a real sequence in $[0,1]$ satisfying the condition $\epsilon \leq \alpha_{n} \leq 1-\epsilon$ for all $n \geq 1$ and for some $\epsilon>0$. Then the sequence $\left\{x_{n}\right\}$ generated from arbitrary $x_{1} \in K$ by

$$
x_{n+1}=\left(1-\alpha_{n}\right) x_{n}+\alpha_{n} T^{n} x_{n}, \quad n \geq 1,
$$

converges strongly to a fixed point of $T$.

Theorem 1.2 (see [9]). Let E be a uniformly convex Banach space satisfying Opial's condition, $K$ a nonempty closed convex and bounded subset of $E$, and $T: K \rightarrow K$ an asymptotically nonexpansive with sequence $\left\{k_{n}\right\} \subset[1, \infty), k_{n} \rightarrow 1$, and $\sum_{n=1}^{\infty}\left(k_{n}^{2}-1\right)<\infty$. Let $\left\{\alpha_{n}\right\}_{n=1}^{\infty}$ be a real sequence in $[0,1]$ satisfying the condition $0<a \leq \alpha_{n} \leq b<1$ for all $n \geq 1$ and some $a, b \in(0,1)$. Then the sequence $\left\{x_{n}\right\}$ generated from arbitrary $x_{1} \in K$ by

$$
x_{n+1}=\left(1-\alpha_{n}\right) x_{n}+\alpha_{n} T^{n} x_{n}, \quad n \geq 1,
$$

converges weakly to a fixed point of $T$.

Subsequently, Tan and $\mathrm{Xu}$ [13] first proved that Schu's theorem remains true if the assumption that $E$ satisfies Opial's condition is replaced by the one that $E$ has a Fréchet differential norm. Meantime, Tan and Xu [13] proved the weak convergence of the modified Ishikawa iterative scheme in a uniformly convex Banach space which either satisfies Opial's condition or has a Fréchet differential norm. In [7], Rhoades extended [8, Theorem 1.1] to uniformly convex Banach space using a modified Ishikawa iteration method. In [6], Osilike and Aniagbosor proved that the theorems of Schu and Rhoades remain true without the boundedness condition imposed on $K$, provided that $F(T)=\{x \in K$ : $T x=x\} \neq \varnothing$.

In [12], Tan and $\mathrm{Xu}$ introduced a modified Ishikawa process to approximate fixed points of nonexpansive mappings defined on nonempty closed convex bounded subsets of a uniformly convex Banach space $E$. More precisely, they proved the following theorem.

Theorem 1.3 (see [12]). Let E be a uniformly convex Banach space which satisfies Opial's condition or has a Fréchet differentiable norm and $C$ a nonempty closed convex bounded subset of $E, T: C \rightarrow C$ a nonexpansive mapping and let $\left\{\alpha_{n}\right\},\left\{\beta_{n}\right\}$ be real sequences in $[0,1]$ such that $\sum_{n=1}^{\infty} \alpha_{n}\left(1-\alpha_{n}\right)=\infty$ and $\sum_{n=1}^{\infty} \beta_{n}\left(1-\alpha_{n}\right)=\infty$. Then the sequence $\left\{x_{n}\right\}$ generated from arbitrary $x_{1} \in C$ by

$$
x_{n+1}=\left(1-\alpha_{n}\right) x_{n}+\alpha_{n} T\left[\left(1-\beta_{n}\right) x_{n}+\beta_{n} T x_{n}\right], \quad n \geq 1 \text {, }
$$

converges weakly to a fixed point of $T$.

In the above results, $T$ remains a self-mapping of a nonempty closed convex subset $K$ of a uniformly convex Banach space if, however, the domain $K$ of $T$ is a proper subset 
of $E$ (and this is the case in several applications), and $T$ maps $K$ into $E$, then iteration processes of Mann and Ishikawa studied by these authors may fail to be well defined.

Chidume [1] studied the iteration scheme defined by

$$
x_{1} \in K, \quad x_{n+1}=P\left(\left(1-\alpha_{n}\right) x_{n}+\alpha_{n} T(P T)^{n-1} x_{n}\right), \quad n \geq 1,
$$

in the framework of uniformly convex Banach space, where $K$ is a nonempty closed convex nonexpansive retract of a real uniformly convex Banach space $E$ with $P$ as a nonexpansive retraction. $T: K \rightarrow E$ is an asymptotically nonexpansive nonselfmap with sequence $\left\{k_{n}\right\} \subset[1, \infty), k_{n} \rightarrow 1 .\left\{\alpha_{n}\right\}_{n=1}^{\infty}$ is a real sequence in $[0,1]$ satisfying the condition $\epsilon \leq \alpha_{n} \leq 1-\epsilon$ for all $n \geq 1$ and for some $\epsilon>0$. They proved strong and weak convergence theorems for asymptotically nonexpansive nonselfmaps.

Recently, Shahzad [11] studied the sequence $\left\{x_{n}\right\}$ defined by

$$
x_{1} \in K, \quad x_{n+1}=P\left(\left(1-\alpha_{n}\right) x_{n}+\alpha_{n} T P\left[\left(1-\beta_{n}\right) x_{n}+\beta_{n} T x_{n}\right]\right),
$$

where $K$ is a nonempty closed convex nonexpansive retract of a real uniformly convex Banach space $E$ with $P$ as a nonexpansive retraction. He proved weak and strong convergence theorems for nonself nonexpansive mappings in Banach spaces.

Motivated by Chidume [1], Shahzad [11], and some others, the purpose of this paper is to construct an iterative scheme for approximating a fixed point of asymptotically nonexpansive nonself maps (when such a fixed point exists) and to prove some strong and weak convergence theorems for such maps.

Let $K$ be a nonempty closed convex subset of a real uniformly convex Banach space $E$. In this paper, the following iteration scheme is studied:

$$
\begin{gathered}
x_{1} \in K, \\
z_{n}=P\left(\alpha_{n}^{\prime \prime} T(P T)^{n-1} x_{n}+\left(1-\alpha_{n}^{\prime \prime}\right) x_{n}\right), \\
y_{n}=P\left(\alpha_{n}^{\prime} T(P T)^{n-1} z_{n}+\left(1-\alpha_{n}^{\prime}\right) x_{n}\right), \\
x_{n+1}=P\left(\alpha_{n} T(P T)^{n-1} y_{n}+\left(1-\alpha_{n}\right) x_{n}\right),
\end{gathered}
$$

where $\left\{\alpha_{n}\right\},\left\{\alpha_{n}^{\prime}\right\}$, and $\left\{\alpha_{n}^{\prime \prime}\right\}$ are real sequences in $(0,1)$.

Our theorems improve and generalize some previous results. Our weak convergence result applies not only to $L^{p}$-spaces with $1<p<\infty$ but also to other spaces which do not satisfy Opial's condition or have a Fréchet differentiable norm. More precisely, we prove weak convergence of the modified Noor-type iteration process (Noor-type iteration process was introduced by Xu and Noor [14]) in a uniformly convex Banach space whose dual has the Kadec-Klee property. It is worth mentioning that there are uniformly convex Banach spaces, which have neither a Fréchet differentiable norm nor Opial's property; however their dual does have the Kadec-Klee property (see, e.g., [3, 5]).

Let $E$ be a real Banach space. A subset $K$ of $E$ is said to be a retract of $E$ if there exists a continuous map $P: E \rightarrow E$ such that $P x=x$ for all $x \in K$. A map $P: E \rightarrow E$ is said to be a retraction if $P^{2}=P$. It follows that if a map $P$ is a retraction, then $P y=y$ for all $y$ in the range of $P$. A set $K$ is optimal if each point outside $K$ can be moved to be closer to all 
points of $K$. It is well known (see, e.g., [2]) that

(i) if $E$ is a separable, strictly convex, smooth, reflexive Banach space, and if $K \subset E$ is an optimal set with interior, then $K$ is a nonexpansive retract of $E$;

(ii) a subset of $l^{p}$, with $1<p<\infty$, is a nonexpansive retract if and only if it is optimal.

Note that every nonexpansive retract is optimal. In strictly convex Banach spaces, optimal sets are closed and convex. However, every closed convex subset of a Hilbert space is optimal and also a nonexpansive retract.

A mapping $T$ with domain $D(T)$ and range $R(T)$ in $E$ is said to be demiclosed at $p$ if whenever $\left\{x_{n}\right\}$ is a sequence in $D(T)$ such that $\left\{x_{n}\right\}$ converges weakly to $x^{*} \in D(T)$ and $\left\{T x_{n}\right\}$ converges strongly to $p$, then $T x^{*}=p$.

A Banach space $E$ is said to have the Kadec-Klee property if for every sequence $\left\{x_{n}\right\}$ in $E, x_{n} \rightarrow x$ weakly and $\left\|x_{n}\right\| \rightarrow\|x\|$ strongly together imply $\left\|x_{n}-x\right\| \rightarrow 0$.

Recall that the mapping $T: K \rightarrow E$ with $F(T) \neq \varnothing$, where $K$ is a subset of $E$, is said to satisfy $[10$, condition (A) $]$ if there is a nondecreasing function $f:[0, \infty) \rightarrow[0, \infty)$ with $f(0)=0$ and $f(r)>0$ for all $r \in(0, \infty)$ such that for all $x \in K$,

$$
\|x-T x\| \geq f(d(x, F(T)))
$$

where $d(x, F(T))=\inf \{\|x-p\|: p \in F(T)\}$.

In order to prove our main results, we will make use of the following lemmas.

Lemma 1.4 (Schu [9]). Suppose that $E$ is a uniformly convex Banach space and $0<p \leq$ $t_{n} \leq q<1$ for all $n \in \mathbb{N}$. Suppose further that $\left\{x_{n}\right\}$ and $\left\{y_{n}\right\}$ are sequences of $E$ such that

$$
\begin{gathered}
\limsup _{n \rightarrow \infty}\left\|x_{n}\right\| \leq r, \quad \limsup _{n \rightarrow \infty}\left\|y_{n}\right\| \leq r, \\
\lim _{n \rightarrow \infty}\left\|t_{n} x_{n}+\left(1-t_{n}\right) y_{n}\right\|=r
\end{gathered}
$$

hold for some $r \geq 0$. Then $\lim _{n \rightarrow \infty}\left\|x_{n}-y_{n}\right\|=0$.

Lemma 1.5 (demiclosed principle for nonselfmap [1]). Let E be a uniformly convex Banach space, $K$ a nonempty closed convex subset of $E$. Let $T: K \rightarrow E$ be an asymptotically nonexpansive mapping with $\left\{k_{n}\right\} \subset[1, \infty)$ and $k_{n} \rightarrow 1$ as $n \rightarrow \infty$. Then $I-T$ is demiclosed with respect to zero.

Lemma 1.6 (see [3]). Let $E$ be a real reflexive Banach space such that its dual $E^{*}$ has the Kadec-Klee property. Let $\left\{x_{n}\right\}$ be a bounded sequence in $E$ and $x^{*}, y^{*} \in w_{w}\left(x_{n}\right)$; here $w_{w}\left(x_{n}\right)$ denotes the weak $w$-limit set of $\left\{x_{n}\right\}$. Suppose $\lim _{n \rightarrow \infty}\left\|t x_{n}+(1-t) x^{*}-y^{*}\right\|$ exists for all $t \in[0,1]$. Then $x^{*}=y^{*}$.

Lemma 1.7 (Tan and $\mathrm{Xu}[12]$ ). Let $\left\{r_{n}\right\},\left\{s_{n}\right\}$, and $\left\{t_{n}\right\}$ be three nonnegative sequences satisfying the following conditions:

$$
r_{n+1} \leq\left(1+s_{n}\right) r_{n}+t_{n} \quad \forall n \geq 1
$$

If $\sum_{n=1}^{\infty} s_{n}<\infty$ and $\sum_{n=1}^{\infty} t_{n}<\infty$, then $\lim _{n \rightarrow \infty} r_{n}$ exists. 


\section{Main results}

Definition 2.1 (see [1]). Let $E$ be a real-normed linear space, $K$ a nonempty subset of $E$. Let $P: E \rightarrow K$ be the nonexpansive retraction of $E$ onto $K$. A map $T: K \rightarrow E$ is said to be an asymptotically nonexpansive mapping if there exists a sequence $\left\{k_{n}\right\} \subset[1, \infty)$ and $k_{n} \rightarrow 1$ as $n \rightarrow \infty$ such that the following inequality holds:

$$
\left\|T(P T)^{n-1} x-T(P T)^{n-1} y\right\| \leq k_{n}\|x-y\| \quad \forall x, y \in K, n \geq 1 .
$$

$T$ is called uniformly $L$-Lipschitzian if there exists $L>0$ such that

$$
\left\|T(P T)^{n-1} x-T(P T)^{n-1} y\right\| \leq L\|x-y\| \quad \forall x, y \in K, n \geq 1 .
$$

Lemma 2.2. Let $E$ be a uniformly convex Banach space and $K$ a nonempty closed convex subset which is also a nonexpansive retract of $E$. Let $T: K \rightarrow E$ be an asymptotically nonexpansive mapping with $\left\{k_{n}\right\} \subset[1, \infty)$ such that $\sum_{n=1}^{\infty}\left(k_{n}-1\right)<\infty$. Starting from arbitrary $x_{1} \in K$, define the sequence $\left\{x_{n}\right\}$ by the recursion (1.7). Then $\lim _{n \rightarrow \infty}\left\|x_{n}-p\right\|$ exists, for any $p \in F(T)$, where $F(T)$ denotes the nonempty fixed points set of $T$.

Proof. For any given $p \in F(T)$, it follows from (1.7) that

$$
\begin{aligned}
\left\|z_{n}-p\right\| & =\left\|P\left(\alpha_{n}^{\prime \prime} T(P T)^{n-1} x_{n}+\left(1-\alpha_{n}^{\prime \prime}\right) x_{n}\right)-p\right\| \\
& \leq\left\|\alpha_{n}^{\prime \prime} T(P T)^{n-1} x_{n}+\left(1-\alpha_{n}^{\prime \prime}\right) x_{n}-p\right\| \\
& \leq \alpha_{n}^{\prime \prime}\left\|T(P T)^{n-1} x_{n}-p\right\|+\left(1-\alpha_{n}^{\prime \prime}\right)\left\|x_{n}-p\right\| \\
& \leq \alpha_{n}^{\prime \prime} k_{n}\left\|x_{n}-p\right\|+\left(1-\alpha_{n}^{\prime \prime}\right)\left\|x_{n}-p\right\| \\
& \leq k_{n}\left\|x_{n}-p\right\| .
\end{aligned}
$$

That is,

$$
\left\|z_{n}-p\right\| \leq k_{n}\left\|x_{n}-p\right\|
$$

From (1.7) and (2.4) we get

$$
\begin{aligned}
\left\|y_{n}-p\right\| & =\left\|P\left(\alpha_{n}^{\prime} T(P T)^{n-1} z_{n}+\left(1-\alpha_{n}^{\prime}\right) x_{n}\right)-p\right\| \\
& \leq\left\|\alpha_{n}^{\prime} T(P T)^{n-1} z_{n}+\left(1-\alpha_{n}^{\prime}\right) x_{n}-p\right\| \\
& \leq \alpha_{n}^{\prime}\left\|T(P T)^{n-1} z_{n}-p\right\|+\left(1-\alpha_{n}^{\prime}\right)\left\|x_{n}-p\right\| \\
& \leq \alpha_{n}^{\prime} k_{n}\left\|z_{n}-p\right\|+\left(1-\alpha_{n}^{\prime}\right)\left\|x_{n}-p\right\| \\
& \leq k_{n}^{2}\left\|x_{n}-p\right\| .
\end{aligned}
$$


6 Asymptotically nonexpansive mappings

That is,

$$
\left\|y_{n}-p\right\| \leq k_{n}^{2}\left\|x_{n}-p\right\|
$$

Again, from (1.7) and (2.6) we have

$$
\begin{aligned}
\left\|x_{n+1}-p\right\| & =\left\|P\left(\alpha_{n} T(P T)^{n-1} y_{n}+\left(1-\alpha_{n}\right) x_{n}\right)-p\right\| \\
& =\left\|\alpha_{n} T(P T)^{n-1} y_{n}+\left(1-\alpha_{n}\right) x_{n}-p\right\| \\
& \leq \alpha_{n}\left\|T(P T)^{n-1} y_{n}-p\right\|+\left(1-\alpha_{n}\right)\left\|x_{n}-p\right\| \\
& \leq \alpha_{n} k_{n}\left\|y_{n}-p\right\|+\left(1-\alpha_{n}\right)\left\|x_{n}-p\right\| \\
& \leq \alpha_{n} k_{n}^{3}\left\|x_{n}-p\right\|+\left(1-\alpha_{n}\right)\left\|x_{n}-p\right\| \\
& \leq k_{n}^{3}\left\|x_{n}-p\right\| .
\end{aligned}
$$

That is,

$$
\left\|x_{n+1}-p\right\| \leq\left(1+\left(k_{n}^{3}-1\right)\right)\left\|x_{n}-p\right\| .
$$

Note that $\sum_{n=1}^{\infty}\left(k_{n}-1\right)<\infty$ is equivalent to $\sum_{n=1}^{\infty}\left(k_{n}^{3}-1\right)<\infty$, therefore by Lemma 1.7, $\lim _{n \rightarrow \infty}\left\|x_{n}-p\right\|$ exists for all $p \in F(T)$. This completes the proof.

Lemma 2.3. Let $E$ be a normed linear space, $K$ a nonempty closed convex subset which is also a nonexpansive retract of $E, T: K \rightarrow E$ a uniformly L-Lipschitzian, starting from arbitrary $x_{1} \in K$, define the sequence $\left\{x_{n}\right\}$ by the recursion (1.7) and set $C_{n}=\left\|x_{n}-T(P T)^{n-1} x_{n}\right\|$ for all $n \geq 1$. If $\lim _{n \rightarrow \infty} C_{n}=0$, then $\lim _{n \rightarrow \infty}\left\|x_{n}-T x_{n}\right\|=0$.

Proof. It follows from (1.7) that

$$
\begin{aligned}
\left\|x_{n+1}-x_{n}\right\| & \leq\left\|\alpha_{n} T(P T)^{n-1} y_{n}+\left(1-\alpha_{n}\right) x_{n}-x_{n}\right\| \\
& \leq\left\|T(P T)^{n-1} y_{n}-x_{n}\right\| \\
& \leq\left\|T(P T)^{n-1} x_{n}-x_{n}\right\|+\left\|T(P T)^{n-1} y_{n}-T(P T)^{n-1} x_{n}\right\| \\
& \leq C_{n}+L\left\|y_{n}-x_{n}\right\| \\
& \leq C_{n}+L\left\|\alpha_{n}^{\prime} T(P T)^{n-1} z_{n}+\left(1-\alpha_{n}^{\prime}\right) x_{n}-x_{n}\right\| \\
& \leq C_{n}+L\left\|T(P T)^{n-1} z_{n}-x_{n}\right\| \\
& \leq C_{n}+L\left\|T(P T)^{n-1} x_{n}-x_{n}\right\|+L\left\|T(P T)^{n-1} z_{n}-T(P T)^{n-1} x_{n}\right\| \\
& \leq C_{n}+L C_{n}+L^{2}\left\|z_{n}-x_{n}\right\| \\
& \leq C_{n}+L C_{n}+L^{2}\left\|\alpha_{n}^{\prime \prime} T(P T)^{n-1} x_{n}+\left(1-\alpha_{n}^{\prime \prime}\right) x_{n}-x_{n}\right\| \\
& \leq C_{n}\left(1+L+L^{2}\right),
\end{aligned}
$$




$$
\begin{aligned}
\left\|y_{n-1}-x_{n}\right\| & \leq\left\|\alpha_{n-1}^{\prime} T(P T)^{n-2} z_{n-1}+\left(1-\alpha_{n-1}^{\prime}\right) x_{n-1}-x_{n}\right\| \\
& \leq\left\|T(P T)^{n-2} z_{n-1}-x_{n-1}\right\|+\left\|x_{n-1}-x_{n}\right\| \\
& \leq\left\|T(P T)^{n-2} x_{n-1}-x_{n-1}\right\|+\left\|T(P T)^{n-2} z_{n-1}-T(P T)^{n-2} x_{n-1}\right\|+\left\|x_{n-1}-x_{n}\right\| \\
& \leq C_{n-1}+L C_{n-1}+\left\|x_{n-1}-x_{n}\right\| .
\end{aligned}
$$

Substituting (2.9) into (2.10) we obtain

$$
\left\|y_{n-1}-x_{n}\right\| \leq C_{n-1}\left(2+2 L+L^{2}\right)
$$

On the other hand, from (2.9) and (2.11) we have

$$
\begin{aligned}
\left\|x_{n}-(P T)^{n-1} x_{n}\right\| \leq & \left\|\alpha_{n-1} T(P T)^{n-2} y_{n-1}+\left(1-\alpha_{n-1}\right) x_{n-1}-T(P T)^{n-2} x_{n}\right\| \\
\leq & \left\|T(P T)^{n-2} y_{n-1}-T(P T)^{n-2} x_{n}\right\|+\left\|x_{n-1}-T(P T)^{n-2} x_{n}\right\| \\
\leq & L\left\|y_{n-1}-x_{n}\right\|+\left\|x_{n-1}-T(P T)^{n-2} x_{n-1}\right\| \\
& +\left\|T(P T)^{n-2} x_{n-1}-T(P T)^{n-2} x_{n}\right\| \\
\leq & L\left\|y_{n-1}-x_{n}\right\|+C_{n-1}+L\left\|x_{n-1}-x_{n}\right\| \\
\leq & L C_{n-1}\left(3+3 L+2 L^{2}\right)+C_{n-1} .
\end{aligned}
$$

It follows from (2.12) that

$$
\begin{aligned}
\left\|x_{n}-T x_{n}\right\| & \leq\left\|x_{n}-T(P T)^{n-1} x_{n}\right\|+\left\|T(P T)^{n-1} x_{n}-T x_{n}\right\| \\
& \leq C_{n}+L\left\|(P T)^{n-1} x_{n}-x_{n}\right\| \\
& \leq C_{n}+L C_{n-1}\left(1+3 L+3 L^{2}+2 L^{3}\right) .
\end{aligned}
$$

It follows from $\lim _{n \rightarrow \infty} C_{n}=0$ that

$$
\lim _{n \rightarrow \infty}\left\|x_{n}-T x_{n}\right\|=0
$$

This completes the proof.

Theorem 2.4. Let $E$ be a uniformly convex Banach space and $K$ a nonempty closed convex subset which is also a nonexpansive retract of $E$. Let $T: K \rightarrow E$ be an asymptotically nonexpansive mapping with $\left\{k_{n}\right\} \subset[1, \infty)$ such that $\sum_{n=1}^{\infty}\left(k_{n}-1\right)<\infty$ and $F(T) \neq \varnothing$. Let $\left\{\alpha_{n}\right\}$, $\left\{\alpha_{n}^{\prime}\right\}$, and $\left\{\alpha_{n}^{\prime \prime}\right\}$ be real sequences in $(0,1)$ and $\epsilon \leq \alpha_{n}, \alpha_{n}^{\prime}, \alpha_{n}^{\prime \prime} \leq 1-\epsilon$ for all $n \in \mathbb{N}$ and some $\epsilon>0$, starting from arbitrary $x_{1} \in K$, define the sequence $\left\{x_{n}\right\}$ by the recursion (1.7). Then $\lim _{n \rightarrow \infty}\left\|x_{n}-T x_{n}\right\|=0$.

Proof. Take $p \in F(T)$, by Lemma 2.2 we know $\lim _{n \rightarrow \infty}\left\|x_{n}-p\right\|$ exists. Let $\lim _{n \rightarrow \infty} \| x_{n}-$ $p \|=c$. If $c=0$, then by the continuity of $T$ the conclusion follows. Now suppose $c>0$. We claim $\lim _{n \rightarrow \infty}\left\|T x_{n}-x_{n}\right\|=0$. Taking limsup on both sides in the inequality (2.4), we 
8 Asymptotically nonexpansive mappings

have

$$
\limsup _{n \rightarrow \infty}\left\|z_{n}-p\right\| \leq c .
$$

Similarly, taking limsup on both sides in the inequality (2.6), we have

$$
\limsup _{n \rightarrow \infty}\left\|y_{n}-p\right\| \leq c
$$

Next, we consider

$$
\left\|T(P T)^{n-1} y_{n}-p\right\| \leq k_{n}\left\|y_{n}-p\right\| .
$$

Taking limsup on both sides in the above inequality and using (2.16), we get

$$
\limsup _{n \rightarrow \infty}\left\|T(P T)^{n-1} y_{n}-p\right\| \leq c .
$$

Again, $\lim _{n \rightarrow \infty}\left\|x_{n+1}-p\right\|=c$ means that

$$
\liminf _{n \rightarrow \infty}\left\|\alpha_{n}\left(T(P T)^{n-1} y_{n}-p\right)+\left(1-\alpha_{n}\right)\left(x_{n}-p\right)\right\| \geq c .
$$

On the other hand, we have

$$
\begin{aligned}
\| \alpha_{n}( & \left.T(P T)^{n-1} y_{n}-p\right)+\left(1-\alpha_{n}\right)\left(x_{n}-p\right) \| \\
& \leq \alpha_{n}\left\|T(P T)^{n-1} y_{n}-p\right\|+\left(1-\alpha_{n}\right)\left\|x_{n}-p\right\| \\
& \leq \alpha_{n} k_{n}\left\|y_{n}-p\right\|+\left(1-\alpha_{n}\right)\left\|x_{n}-p\right\| \\
& \leq \alpha_{n} k_{n}^{3}\left\|x_{n}-p\right\|+\left(1-\alpha_{n}\right)\left\|x_{n}-p\right\| \\
& \leq k_{n}^{3}\left\|x_{n}-p\right\| .
\end{aligned}
$$

Therefore, we obtain

$$
\limsup _{n \rightarrow \infty}\left\|\alpha_{n}\left(T(P T)^{n-1} y_{n}-p\right)+\left(1-\alpha_{n}\right)\left(x_{n}-p\right)\right\| \leq c .
$$

Combining (2.19) and (2.21), we obtain

$$
\lim _{n \rightarrow \infty}\left\|\alpha_{n}\left(T(P T)^{n-1} y_{n}-p\right)+\left(1-\alpha_{n}\right)\left(x_{n}-p\right)\right\|=c .
$$

Hence applying Lemma 1.4, we have

$$
\lim _{n \rightarrow \infty}\left\|T(P T)^{n-1} y_{n}-x_{n}\right\|=0 .
$$

Next, it follows from

$$
\begin{aligned}
\left\|x_{n}-p\right\| & \leq\left\|T(P T)^{n-1} y_{n}-x_{n}\right\|+\left\|T(P T)^{n-1} y_{n}-p\right\| \\
& \leq\left\|T(P T)^{n-1} y_{n}-x_{n}\right\|+k_{n}\left\|y_{n}-p\right\|
\end{aligned}
$$


that we have

$$
c \leq \liminf _{n \rightarrow \infty}\left\|y_{n}-p\right\| \leq \limsup _{n \rightarrow \infty}\left\|y_{n}-p\right\| \leq c .
$$

That is,

$$
\lim _{n \rightarrow \infty}\left\|y_{n}-p\right\|=c
$$

Again, $\lim _{n \rightarrow \infty}\left\|y_{n}-p\right\|=c$ gives that

$$
\liminf _{n \rightarrow \infty}\left\|\alpha_{n}^{\prime}\left(T(P T)^{n-1} z_{n}-p\right)+\left(1-\alpha_{n}^{\prime}\right)\left(x_{n}-p\right)\right\| \geq c
$$

Similarly,

$$
\begin{aligned}
\| \alpha_{n}^{\prime}( & \left.T(P T)^{n-1} z_{n}-p\right)+\left(1-\alpha_{n}^{\prime}\right)\left(x_{n}-p\right) \| \\
& \leq \alpha_{n}^{\prime}\left\|T(P T)^{n-1} z_{n}-p\right\|+\left(1-\alpha_{n}^{\prime}\right)\left\|x_{n}-p\right\| \\
& \leq \alpha_{n}^{\prime} k_{n}\left\|z_{n}-p\right\|+\left(1-\alpha_{n}^{\prime}\right)\left\|x_{n}-p\right\| \\
& \leq \alpha_{n}^{\prime} k_{n}^{2}\left\|x_{n}-p\right\|+\left(1-\alpha_{n}^{\prime}\right)\left\|x_{n}-p\right\| \\
& \leq k_{n}^{2}\left\|x_{n}-p\right\| .
\end{aligned}
$$

Therefore, we have

$$
\limsup _{n \rightarrow \infty}\left\|\alpha_{n}^{\prime}\left(T(P T)^{n-1} z_{n}-p\right)+\left(1-\alpha_{n}^{\prime}\right)\left(x_{n}-p\right)\right\| \leq c .
$$

Combining (2.27) and (2.29) yields

$$
\lim _{n \rightarrow \infty}\left\|\alpha_{n}^{\prime}\left(T(P T)^{n-1} z_{n}-p\right)+\left(1-\alpha_{n}^{\prime}\right)\left(x_{n}-p\right)\right\|=c .
$$

On the other hand, we have

$$
\left\|T(P T)^{n-1} z_{n}-p\right\| \leq k_{n}\left\|z_{n}-p\right\| .
$$

Taking limsup on both sides in the above inequality and using (2.15), we have

$$
\limsup _{n \rightarrow \infty}\left\|T(P T)^{n-1} z_{n}-p\right\| \leq c
$$

Applying Lemma 1.4, it follows from (2.30) and (2.32) that

$$
\lim _{n \rightarrow \infty}\left\|T(P T)^{n-1} z_{n}-x_{n}\right\|=0 .
$$


Notice that

$$
\begin{aligned}
\left\|x_{n}-p\right\| & \leq\left\|T(P T)^{n-1} z_{n}-x_{n}\right\|+\left\|T(P T)^{n-1} z_{n}-p\right\| \\
& \leq\left\|T(P T)^{n-1} z_{n}-x_{n}\right\|+k_{n}\left\|z_{n}-p\right\|
\end{aligned}
$$

which yields

$$
c \leq \liminf _{n \rightarrow \infty}\left\|z_{n}-p\right\| \leq \limsup _{n \rightarrow \infty}\left\|z_{n}-p\right\| \leq c .
$$

That is,

$$
\lim _{n \rightarrow \infty}\left\|z_{n}-p\right\|=c
$$

Using the same method, we have

$$
\lim _{n \rightarrow \infty}\left\|\alpha_{n}^{\prime \prime}\left(T(P T)^{n-1} x_{n}-p\right)+\left(1-\alpha_{n}^{\prime \prime}\right)\left(x_{n}-p\right)\right\|=c .
$$

Moreover,

$$
\begin{aligned}
\left\|T(P T)^{n-1} x_{n}-p\right\| & \leq\left\|T(P T)^{n-1} x_{n}-p\right\| \\
& \leq k_{n}\left\|x_{n}-p\right\|
\end{aligned}
$$

which implies that

$$
\limsup _{n \rightarrow \infty}\left\|T(P T)^{n-1} x_{n}-p\right\| \leq c .
$$

Lemma 1.4 combined with (2.37) and (2.39) yields

$$
\lim _{n \rightarrow \infty}\left\|T(P T)^{n-1} x_{n}-x_{n}\right\|=0 .
$$

Since $T$ is uniformly L-Lipschitzian for some $L>0$, it follows from Lemma 2.3 that

$$
\lim _{n \rightarrow \infty}\left\|x_{n}-T x_{n}\right\|=0
$$

This completes the proof.

Lemma 2.5. Let $E$ be a uniformly convex Banach space and $K$ a nonempty closed convex subset which is also a nonexpansive retract of $E$. Let $T: K \rightarrow E$ be an asymptotically nonexpansive mapping with $F(T) \neq \varnothing$ and $\left\{k_{n}\right\} \subset[1, \infty)$ such that $\sum_{n=1}^{\infty}\left(k_{n}-1\right)<\infty$. Let $\left\{\alpha_{n}\right\}$, $\left\{\alpha_{n}^{\prime}\right\}$, and $\left\{\alpha_{n}^{\prime \prime}\right\}$ be real sequences in $[0,1]$ and $\epsilon \leq \alpha_{n}, \alpha_{n}^{\prime}, \alpha_{n}^{\prime \prime} \leq 1-\epsilon$ for all $n \in \mathbb{N}$ and some $\epsilon>0$, starting from arbitrary $x_{1} \in K$, define the sequence $\left\{x_{n}\right\}$ by the recursion (1.7). Then for all $x^{*}, x^{* *} \in F(T)$, the limit

$$
\lim _{n \rightarrow \infty}\left\|t x_{n}+(1-t) x^{*}-x^{* *}\right\|
$$

exists for all $t \in[0,1]$ 
Proof. It follows from Lemma 2.2 that $\left\{x_{n}\right\}$ is bounded, there exists $\mathbb{R}>0$ such that $\left\{x_{n}\right\} \subset C:=B_{R}(0) \cap K$, where $B_{R}(0)=\{x \in E ;\|x\| \leq \mathbb{R}\}$. Then $C$ is a nonempty closed convex bounded subset of $E$. We follow basically the idea of [12]. Let $a_{n}(t)=\| t x_{n}+(1-$ $t) x^{*}-x^{* *} \|$. Then $\lim _{n \rightarrow \infty} a_{n}(0)=\left\|x^{*}-x^{* *}\right\|$, and from Lemma 2.2, $\lim _{n \rightarrow \infty} a_{n}(1)=$ $\lim _{n \rightarrow \infty}\left\|x_{n}-x^{* *}\right\|$ exists. Without loss of generality, we may assume that $\lim _{n \rightarrow \infty} \| x_{n}-$ $x^{* *} \|=b>0$ and $t \in(0,1)$. Define $T_{n}: C \rightarrow C$ by

$$
\begin{aligned}
T_{n} x=P\left(\alpha_{n} T(P T)^{n-1}\right. & \left(P\left(\alpha_{n}^{\prime} T(P T)^{n-1}\right)\left(P\left(\alpha_{n}^{\prime \prime} T(P T)^{n-1} x\right)+\left(1-\alpha_{n}^{\prime \prime}\right) x\right)\right. \\
+ & \left.\left.\left(1-\alpha_{n}^{\prime}\right) x\right)+\left(1-\alpha_{n}\right) x\right) .
\end{aligned}
$$

Then

$$
\left\|T_{n} x-T_{n} y\right\| \leq k_{n}^{3}\|x-y\| .
$$

Set $S_{n, m}:=T_{n+m-1} T_{n+m-2} \ldots T_{n}, m \geq 1$, and

$$
b_{n, m}=\left\|S_{n, m}\left(t x_{n}+(1-t) x^{*}\right)-\left(t S_{n, m} x_{n}+(1-t) x^{* *}\right)\right\| .
$$

Then

$$
\left\|S_{n, m} x-S_{n, m} y\right\| \leq \prod_{j=n}^{n+m-1} k_{j}^{3}\|x-y\|,
$$

$S_{n, m} x_{n}=x_{n+m}$, and $S_{n, m} p=p$ for all $p \in F(T)$. It follows from [3, Lemma 2.1 and Theorem 2.3] that $\lim _{n \rightarrow \infty} b_{n, m}=0$. Note that

$$
\begin{aligned}
a_{n+m}(t) & =\left\|t x_{n+m}+(1-t) x^{*}-x^{* *}\right\| \\
& \leq b_{n, m}+\left\|S_{n, m}\left(t x_{n}+(1-t) x^{*}\right)-x^{* *}\right\| \\
& \leq b_{n, m}+\prod_{j=n}^{n+m-1} k_{j}^{3} a_{n}(t) .
\end{aligned}
$$

Note that $\sum_{n=1}^{\infty}\left(k_{n}-1\right)<\infty$ is equivalent to $\sum_{n=1}^{\infty}\left(k_{n}^{3}-1\right)<\infty$. Since $k_{n} \in[1, \infty)$, $\lim _{n \rightarrow \infty} \prod_{j=n}^{\infty} k_{j}^{3}=1$. Therefore, we have

$$
\limsup _{n \rightarrow \infty} a_{n}(t) \leq \lim _{n, m \rightarrow \infty} b_{n, m}+\liminf _{n \rightarrow \infty} a_{n}(t)=\liminf _{n \rightarrow \infty} a_{n}(t) .
$$

That is,

$$
\lim _{n \rightarrow \infty}\left\|t x_{n}+(1-t) x^{*}-x^{* *}\right\|
$$

exists for all $t \in[0,1]$. This completes the proof.

Theorem 2.6. Let $E$ be a uniformly convex Banach space such that its dual $E^{*}$ has the Kadec-Klee property and $K$ a nonempty closed convex subset which is also a nonexpansive retract of $E$. Let $T: K \rightarrow E$ be an asymptotically nonexpansive mapping with $\left\{k_{n}\right\} \subset[1, \infty)$, 
$k_{n} \rightarrow 1$ as $n \rightarrow \infty$ and $F(T) \neq \varnothing$. Let $\left\{\alpha_{n}\right\},\left\{\alpha_{n}^{\prime}\right\}$, and $\left\{\alpha_{n}^{\prime \prime}\right\}$ be real sequences in $[0,1]$ and $\epsilon \leq \alpha_{n}, \alpha_{n}^{\prime}, \alpha_{n}^{\prime \prime} \leq 1-\epsilon$ for all $n \in \mathbb{N}$ and some $\epsilon>0$, starting from arbitrary $x_{1} \in K$, define the sequence $\left\{x_{n}\right\}$ by the recursion (1.7). Then $\left\{x_{n}\right\}$ converges weakly to some fixed point of $T$.

Proof. Since $\left\{x_{n}\right\}$ is bounded and $E$ is reflexive, there exists a subsequence $\left\{x_{n_{i}}\right\}$ of $\left\{x_{n}\right\}$ converging weakly to some $u \in k$. It follows from Theorem 2.4 that $\lim _{i \rightarrow \infty}\left\|T x_{n_{i}}-x_{n_{i}}\right\|=$ 0 . By Lemma 1.5 , we have $u=T u$. Next we claim $\left\{x_{n}\right\}$ converges weakly to $u$. Suppose $\left\{x_{n_{j}}\right\}$ is another subsequence of $\left\{x_{n}\right\}$ converging to some $v \in K$. Then $u, v \in w_{w}\left(x_{n}\right) \cap$ $F(T)$. Using Lemma 2.5 yields that the limit

$$
\lim _{n \rightarrow \infty}\left\|t x_{n}+(1-t) u-v\right\|
$$

exists for all $t \in(0,1)$. By Lemma 1.6 we have that $u=v$. Then $\left\{x_{n}\right\}$ converges weakly to some fixed point of $T$.

Next, we will prove a strong convergence theorem.

Theorem 2.7. Let $E$ be a uniformly convex Banach space and $K$ a nonempty closed convex subset which is also a nonexpansive retract of $E$. Let $T: K \rightarrow E$ be a nonexpansive mapping with $p \in F(T):=\{x \in K: T x=x\}$. Let $\left\{\alpha_{n}\right\},\left\{\alpha_{n}^{\prime}\right\}$, and $\left\{\alpha_{n}^{\prime \prime}\right\}$ be real sequences in $[0,1]$ and $\epsilon \leq \alpha_{n}, \alpha_{n}^{\prime}, \alpha_{n}^{\prime \prime} \leq 1-\epsilon$ for all $n \in \mathbb{N}$ and some $\epsilon>0$, starting from arbitrary $x_{1} \in K$, define the sequence $\left\{x_{n}\right\}$ by the recursion (1.7). Suppose T satisfies condition (A). Then $\left\{x_{n}\right\}$ converges strongly to some fixed point of $T$.

Proof. By Lemma 2.2, $\lim _{n \rightarrow \infty}\left\|x_{n}-p\right\|$ exists for all $p \in F=F(T)$. Let $\lim _{n \rightarrow \infty}\left\|x_{n}-p\right\|=$ $c$ for some $c \geq 0$. If $c=0$, there is nothing to prove. Suppose $c>0$. By Theorem 2.4, $\lim _{n \rightarrow \infty}\left\|T x_{n}-x_{n}\right\|=0$, and (2.8) gives

$$
\inf _{p \in F}\left\|x_{n+1}-p\right\| \leq\left(1+\left(k_{n}^{3}-1\right)\right) \inf _{p \in F}\left\|x_{n}-p\right\| .
$$

That is,

$$
d\left(x_{n+1}, F\right) \leq\left(1+\left(k_{n}^{3}-1\right)\right) d\left(x_{n}, F\right)
$$

gives that $\lim _{n \rightarrow \infty} d\left(x_{n}, F\right)$ exists by the virtue of Lemma 1.7. Now by condition (A), $\lim _{n \rightarrow \infty} f\left(d\left(x_{n}, F\right)\right)=0$. Since $f$ is a nondecreasing function and $f(0)=0$, therefore $\lim _{n \rightarrow \infty} d\left(x_{n}, F\right)=0$. Now we can take a subsequence $\left\{x_{n_{j}}\right\}$ of $\left\{x_{n}\right\}$ and sequence $\left\{y_{j}\right\} \subset F$ such that $\left\|x_{n_{j}}-y_{j}\right\|<2^{-j}$. Then following the method of the proof of Tan and Xu [12], we get that $\left\{y_{j}\right\}$ is a Cauchy sequence in $F$ and so it converges. Let $y_{j} \rightarrow y$. Since $F$ is closed, therefore $y \in F$ and then $x_{n_{j}} \rightarrow y$. As $\lim _{n \rightarrow \infty}\left\|x_{n}-p\right\|$ exists, $x_{n} \rightarrow y \in F=F(T)$ thereby completing the proof.

\section{Acknowledgment}

The authors are greatly indebted to the referees for their valuable comments and suggestions which helped to improve this manuscript. 


\section{References}

[1] C. E. Chidume, E. U. Ofoedu, and H. Zegeye, Strong and weak convergence theorems for asymptotically nonexpansive mappings, Journal of Mathematical Analysis and Applications 280 (2003), no. 2, 364-374.

[2] W. J. Davis and P. Enflo, Contractive projections on $l_{p}$ spaces, Analysis at Urbana, Vol. I (Urbana, IL, 1986-1987), London Math. Soc. Lecture Note Ser., vol. 137, Cambridge University Press, Cambridge, 1989, pp. 151-161.

[3] J. García Falset, W. Kaczor, T. Kuczumow, and S. Reich, Weak convergence theorems for asymptotically nonexpansive mappings and semigroups, Nonlinear Analysis. Theory, Methods \& Applications 43 (2001), no. 3, 377-401.

[4] K. Goebel and W. A. Kirk, A fixed point theorem for asymptotically nonexpansive mappings, Proceedings of the American Mathematical Society 35 (1972), 171-174.

[5] W. Kaczor, Weak convergence of almost orbits of asymptotically nonexpansive commutative semigroups, Journal of Mathematical Analysis and Applications 272 (2002), no. 2, 565-574.

[6] M. O. Osilike and S. C. Aniagbosor, Weak and strong convergence theorems for fixed points of asymptotically nonexpansive mappings, Mathematical and Computer Modelling 32 (2000), no. 10, 1181-1191.

[7] B. E. Rhoades, Fixed point iterations for certain nonlinear mappings, Journal of Mathematical Analysis and Applications 183 (1994), no. 1, 118-120.

[8] J. Schu, Iterative construction of fixed points of asymptotically nonexpansive mappings, Journal of Mathematical Analysis and Applications 158 (1991), no. 2, 407-413.

[9] _ Weak and strong convergence to fixed points of asymptotically nonexpansive mappings, Bulletin of the Australian Mathematical Society 43 (1991), no. 1, 153-159.

[10] H. F. Senter and W. G. Dotson Jr., Approximating fixed points of nonexpansive mappings, Proceedings of the American Mathematical Society 44 (1974), no. 2, 375-380.

[11] N. Shahzad, Approximating fixed points of non-self nonexpansive mappings in Banach spaces, Nonlinear Analysis 61 (2005), no. 6, 1031-1039.

[12] K.-K. Tan and H. K. Xu, Approximating fixed points of nonexpansive mappings by the Ishikawa iteration process, Journal of Mathematical Analysis and Applications 178 (1993), no. 2, 301-308.

[13] _ Fixed point iteration processes for asymptotically nonexpansive mappings, Proceedings of the American Mathematical Society 122 (1994), no. 3, 733-739.

[14] B. Xu and M. A. Noor, Fixed-point iterations for asymptotically nonexpansive mappings in Banach spaces, Journal of Mathematical Analysis and Applications 267 (2002), no. 2, 444-453.

Yongfu Su: Department of Mathematics, Tianjin Polytechnic University, Tianjin 300160, China E-mail address: suyongfu@tjpu.edu.cn

Xiaolong Qin: Department of Mathematics, Tianjin Polytechnic University, Tianjin 300160, China

E-mail address: qxlxajh@163.com 


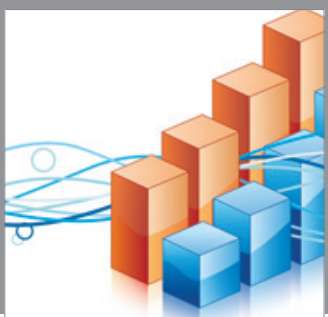

Advances in

Operations Research

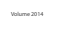

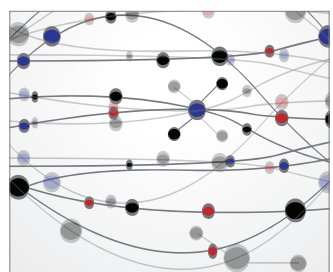

\section{The Scientific} World Journal
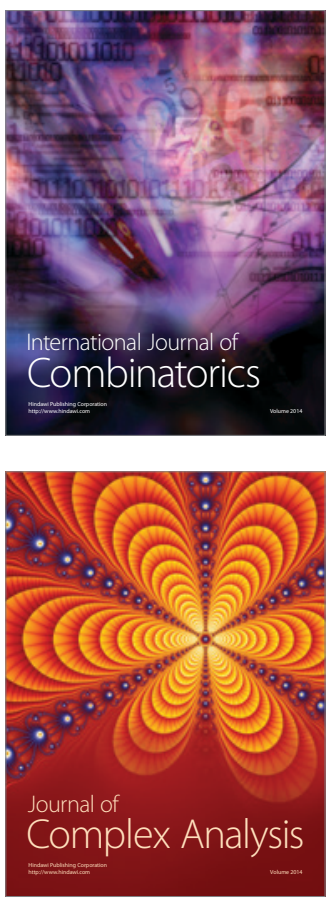

International Journal of

Mathematics and

Mathematical

Sciences
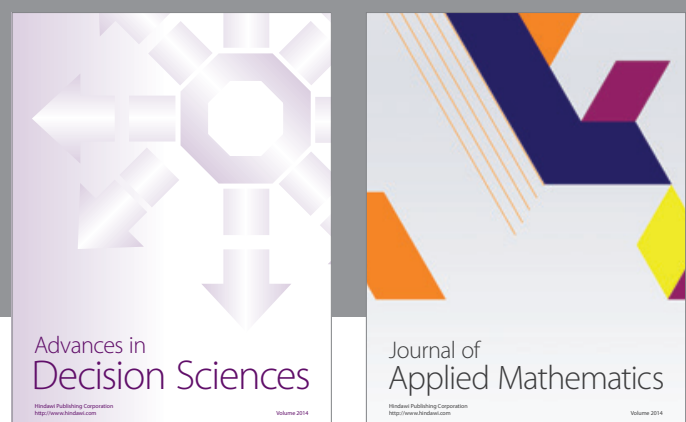

Journal of

Applied Mathematics
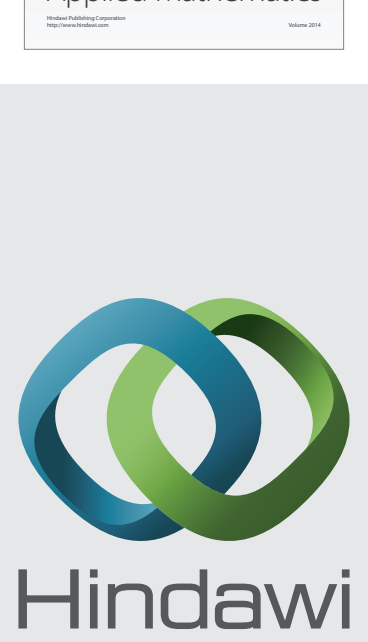

Submit your manuscripts at http://www.hindawi.com
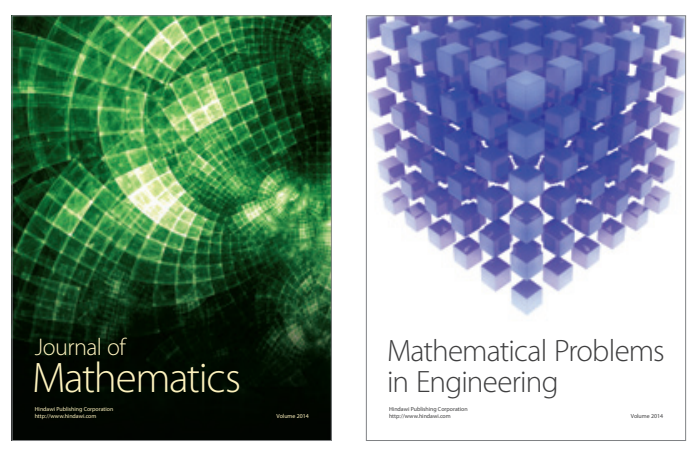

Mathematical Problems in Engineering
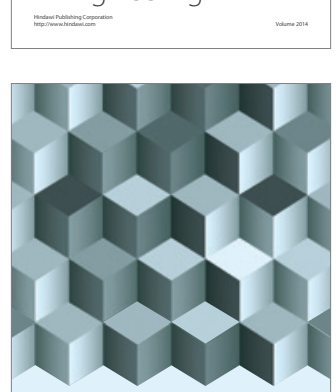

Journal of

Function Spaces
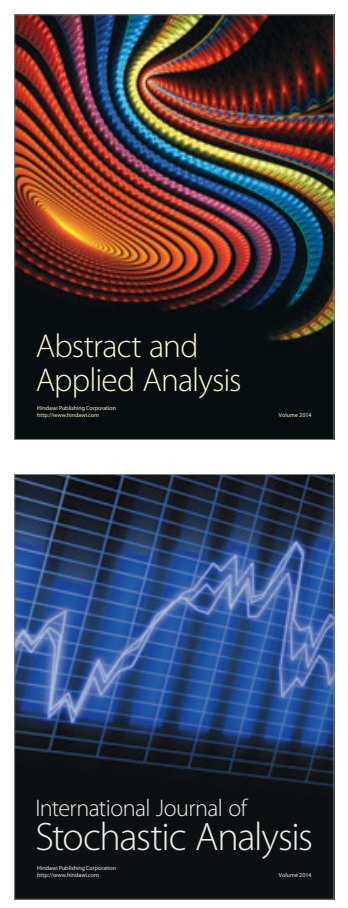

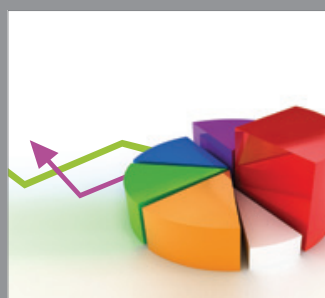

ournal of

Probability and Statistics

Promensencen
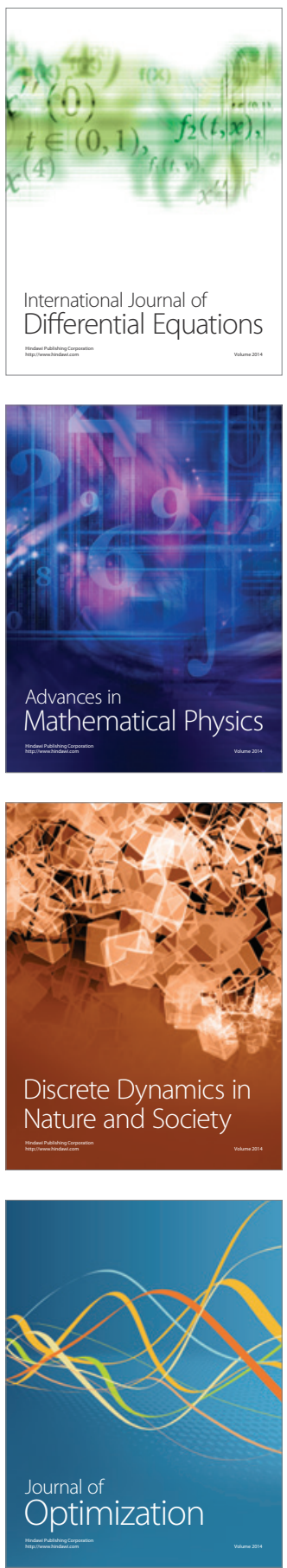